\title{
Gigabecquerel per Gram
}

National Cancer Institute

\section{Source}

National Cancer Institute. Gigabecquerel per Gram. NCI Thesaurus. Code C70525.

A unit of specific radioactivity (massic activity) equal to activity of one gig abecquerel of the sample with total mass of one gram. 